\title{
Aspirin antagonizes the cytotoxic effect of methotrexate in lung cancer cells
}

\author{
KUN-HUANG YAN ${ }^{1,2}$, LIANG-MING LEE ${ }^{1,3^{*}}$, MAO-CHIH HSIEH ${ }^{4 *}$, MING-DE YAN $^{2,5}$, \\ CHIH-JUNG YAO ${ }^{6,7}$, PEY-YI CHANG ${ }^{2}$, TSUNG-LI CHEN ${ }^{2}$, HWAN-YOU CHANG $^{8}$, \\ ANN-LII CHENG ${ }^{9}$, GI-MING LAI ${ }^{2,6,7^{*}}$ and SHUANG-EN CHUANG ${ }^{2 *}$ \\ ${ }^{1}$ Department of Urology, Wan Fang Hospital, Taipei Medical University, Taipei; ${ }^{2}$ National Institute of Cancer Research, \\ National Health Research Institutes, Miaoli; ${ }^{3}$ Department of Urology, School of Medicine, College of Medicine, \\ Taipei Medical University, Taipei; ${ }^{4}$ Division of General Surgery, Department of Surgery, Wan Fang Hospital, \\ Taipei Medical University, Taipei; ${ }^{5}$ Division of Gastroenterology, Department of Internal Medicine, Wan Fang Hospital, \\ Taipei Medical University, Taipei; ${ }^{6}$ Department of Internal Medicine, School of Medicine, College of Medicine, \\ Taipei Medical University, Taipei; ${ }^{7}$ Center of Excellence for Cancer Research, Taipei Medical University, Taipei; \\ ${ }^{8}$ Institute of Molecular Medicine, National Tsing Hua University, Hsinchu; ${ }^{9}$ Departments of Internal Medicine \\ and Oncology, National Taiwan University Hospital, Taipei, Taiwan, R.O.C.
}

Received March 4, 2013; Accepted May 9, 2013

DOI: $10.3892 / o r .2013 .2561$

\begin{abstract}
Methotrexate (MTX) has been widely used for the treatment of cancer and rheumatoid arthritis (RA). Aspirin (ASA) is a non-selective cyclooxygenase (COX) inhibitor that contributes to the treatment of inflammatory conditions such as RA. It has been observed that the antitumor effect of ASA can be attributed to inhibition of cell cycle progression, induction of apoptosis and inhibition of angiogenesis. In the present study, we revealed that the treatment with a combination of MTX and ASA resulted in antagonism of the cytotoxic effect as demonstrated by SRB and colony formation assays. ASA alleviated the MTX-mediated S phase accumulation and recovered the G1 phase. MTX-mediated accumulation of the S phase marker cyclin A was also alleviated by ASA. Notably, FAS protein levels were upregulated by MTX in A549 cells. The antagonism of MTX efficacy caused by ASA was accompanied by altered expression of caspase-3, Bcl-2 and FAS but not dihydrofolate reductase (DHFR). This suggests that the
\end{abstract}

Correspondence to: Dr Shuang-En Chuang, National Institute of Cancer Research, National Health Research Institutes, 35 Keyan Road, Zhunan, Miaoli 35053, Taiwan, R.O.C.

E-mail: sechuang@nhri.org.tw

${ }^{*}$ Contributed equally

Abbreviations: ASA, aspirin; NSAIDs, nonsteroidal antiinflammatory drugs; MTX, methotrexate; DHFR, dihydrofolate reductase

Key words: aspirin, methotrexate, antagonism alteration of caspase-3, Bcl-2 and FAS was involved in the antagonism between ASA and MTX. Exogenously added folic acid reversed the MTX-mediated DHFR inhibition following either MTX or MTX + ASA treatments. Most importantly, we demonstrated for the first time that the commonly used non-steroidal anti-inflammatory drug for headache ASA and possibly other COX-1/2 inhibitors can produce a strong antagonistic effect on the growth inhibition of lung cancer cells when administered in combination with MTX. The clinical implication of our finding is obvious, i.e., the clinical efficacy of MTX therapy can be compromised by ASA and their concomitant use should be avoided.

\section{Introduction}

Antifolates are the first class of antimetabolites introduced to the clinic approximately 60 years ago (1). Methotrexate (MTX), a folic acid antagonist, competitively inhibits dihydrofolate reductase (DHFR) to disrupt cellular folate metabolism. MTX suppresses synthesis of purine and pyrimidine by inhibiting its target enzyme, DHFR (2). MTX reversibly inhibits the proliferation of cells in the late G1 phase and may cause cytotoxicity of cells in the S phase (3). MTX also promotes adenosine release to cause adenosine-mediated suppression of inflammation (4). The adenosine-mediated anti-inflammatory effect of MTX is now supported by clinical data (5). MTX has been widely used since 1985 for the treatment of rheumatoid arthritis (RA) via its presumed anti-proliferative properties (6-8). MTX has also been used in dermatology for more than 5 decades. MTX was introduced to treat severe psoriasis vulgaris in 1951 (9). The anti-psoriatic effect is based on its anti-proliferative, anti-inflammatory and possibly immunosuppressive properties (9). Due to its cytotoxicity, MTX was also demonstrated to be a potent and effective therapy for cancers including leukemia (1) and head and neck cancers (10). After 
years of use of antifolates against malignancies, particularly leukemia, the full understanding of the mechanisms of action of these agents remain unclear (1). A recent report suggests that low-dose MTX is promising for tumor dormancy therapy in patients with osteosarcoma and lung metastasis (11). However, combination treatment of MTX and PUVA may induce cancer (12). To date, much effort has been given to investigate whether MTX combined with traditional chemotherapy drugs and/or radiotherapy produces a synergistic effect in the treatment of various types of cancers.

Aspirin (ASA), a cyclooxygenase (COX)-1/2 inhibitor, has been successful during the past century for its clinical use for anti-inflammatory conditions. Moreover, high doses of ASA (2.5-3.9 g/day) are sometimes used to treat diseases, such as RA $(13,14)$. ASA also nonselectively blocks COX-1 and COX-2 via irreversible acetylation. COX-2 regulates many physiological functions such as augmentation of apoptosis, inhibition of angiogenesis and cell motility. Thus, high COX-2 expression in tumors has been associated with poor survival, and intake of ASA is associated with a decreased risk of various types of cancer including those of the colorectum, stomach, oesophagus, breast, ovary and lung (15-17). ASA may also possess the potential for combination use with standard chemotherapy or radiation therapy. However, a reduction in renal clearance of MTX was observed in patients receiving a maintenance dose of MTX with nonsteroidal anti-inflammatory drugs (NSAIDs) $(18,19)$. The combination of MTX and salicylates was found to greatly increased the frequency of abnormal liver enzyme values (20). Due to its spectrum of effects, the increased toxic side effect of MTX was found to be caused by concomitant administration with ASA in patients (9).

In the present study, we demonstrated that ASA does not increase the anti-proliferative activity of MTX against cancer cells in vitro, rather, ASA antagonizes the therapeutic efficacy of MTX in human lung cancers via preserving cell proliferation and survival. The mechanism involved in the antagonism between MTX and ASA was also investigated.

\section{Materials and methods}

Cell culture. The human lung adenocarcinoma cell lines were maintained in RPMI-1640 (CL1-0 cells) (21) or DMEM (A549 cells) supplemented with $10 \%$ fetal bovine serum and $2 \mathrm{mM}$ L-glutamine, $100 \mu \mathrm{g} / \mathrm{ml}$ streptomycin and $100 \mathrm{U} / \mathrm{ml}$ penicillin, in a humidified $5 \% \mathrm{CO}_{2}$ atmosphere.

Reagents. ASA, MTX and ibuprofen (IBU) were purchased from Sigma Chemical Co. (St. Louis, MO, USA). Celecoxib (CXB) was purchased from Calbiochem (an affiliate of Merck, Germany). The final concentrations of the drug vehicle (DMSO) added to the cell cultures were all $<0.1 \%$.

Cell viability assay. Cell viability was assayed by SRB staining as described previously (22). In brief, cells (1.5x10 $3 /$ well) were seeded on 96 -well plates, followed $24 \mathrm{~h}$ later by treatment with drugs (or vehicle control) for $72 \mathrm{~h}$. Absorbance at $562 \mathrm{~nm}$ was measured with an ELISA reader. Cell viability was expressed as the percentage of absorbance of the drug-treated cells relative to that of the vehicle-treated cells. The combination index (CI) was evaluated by the method of Chou and Talalay $(23,24)$.
Clonogenicity assay. One hundred cells were seeded in a $10-\mathrm{cm}$ culture dish, followed $24 \mathrm{~h}$ later by incubation with the drugs (or vehicle control) for 2 weeks (CL1-0) or 3 weeks (A549). Colonies consisting of $>20$ cells were counted. Colonies were washed with phosphate-buffered saline (PBS), air dried and stained with $0.4 \%$ crystal violet for $1 \mathrm{~min}$, rinsed in water, air dried and photographed.

Cell cycle analysis. Cells (2x105/dish) were plated in $10-\mathrm{cm}$ dishes, followed $24 \mathrm{~h}$ later by treatment with the drugs (or vehicle control) for the intervals indicated. At harvest, cells were trypsinized, washed in PBS and fixed in ice-cold 70\% ethanol in PBS. Cell cycle was assayed by propidium iodide staining, followed by FACScan analysis. Cell cycle profiles were determined using ModFit LT software (Becton-Dickinson, San Diego, CA, USA).

Western blot analysis. At harvest, total protein extracts were prepared, and the concentration was determined using the Bradford method. Aliquots containing $20 \mu \mathrm{g}$ of total protein each were subjected to western blot analysis. Antibodies against cyclin A (sc-239), FAS (sc-8009), caspase-3 (sc-7272) and Bcl-2 (sc-509) were purchased from Santa Cruz Biotechnology, Inc. (Santa Cruz, CA, USA). Antibody against DHFR (15194-1-AP) was purchased from Proteintech Group, Inc. (Chicago, IL, USA).

Reverse transcription (RT)-polymerase chain reaction (PCR) analysis. Total RNA was extracted from cells using TRIzol reagent (Invitrogen, Carlsbad, CA, USA). RT was performed using $1 \mu \mathrm{g}$ of total RNA as a template and random hexamer as a primer. The cDNA was amplified by PCR using FAS- and DHFR-specific primer pairs (DHFR forward primer, GAATCACCCAGGCCATCTTA and reverse, GCCTTTCTC CTCCTGGACAT; Fas forward primer, ACGGAGTTGGGG AAGCTCTT and reverse, TGTCAGTCACTTGGGCATTA ACA). Actin was used as an internal control (actin forward primer: AGCGAGCATCCCCCAAAGTT and reverse, GGG CACGAAGGCTCATCATT). PCR was performed by denaturing the DNA at $94^{\circ} \mathrm{C}$ for $5 \mathrm{~min}$, followed by 30 cycles of amplification: $94^{\circ} \mathrm{C}$ for $30 \mathrm{sec}, 60^{\circ} \mathrm{C}$ for $30 \mathrm{sec}, 72^{\circ} \mathrm{C}$ for $60 \mathrm{sec}$ and a final extension step at $72^{\circ} \mathrm{C}$ for $10 \mathrm{~min}$. Amplified fragments were separated on a $1.0 \%$ agarose gel and visualized with ethidium bromide staining.

Statistical analysis. All data are expressed as means \pm SE. All statistical analyses were performed using the paired t-test (SigmaPlot 2001 software). $\mathrm{P}<0.05$ was considered to indicate a statistically significant result.

\section{Results}

MTX and ASA exert an antagonistic anticancer effect. The anticancer effects of the two drugs, the DHFR inhibitor MTX and the COX-1/2 enzyme inhibitor ASA, were tested individually and in combination, in two human non-small cell lung cancer cell lines, CL1-0 (Fig. 1A-C) and A549 (Fig. 1D-F). As shown in Fig. 1A, while treatment of CL1-0 cells with ASA $2 \mathrm{mM}$ or MTX $12.5 \mathrm{nM}$ alone resulted in $\sim 40$ and $75 \%$ decreases in cell numbers (i.e., 60 and $25 \%$ viability 

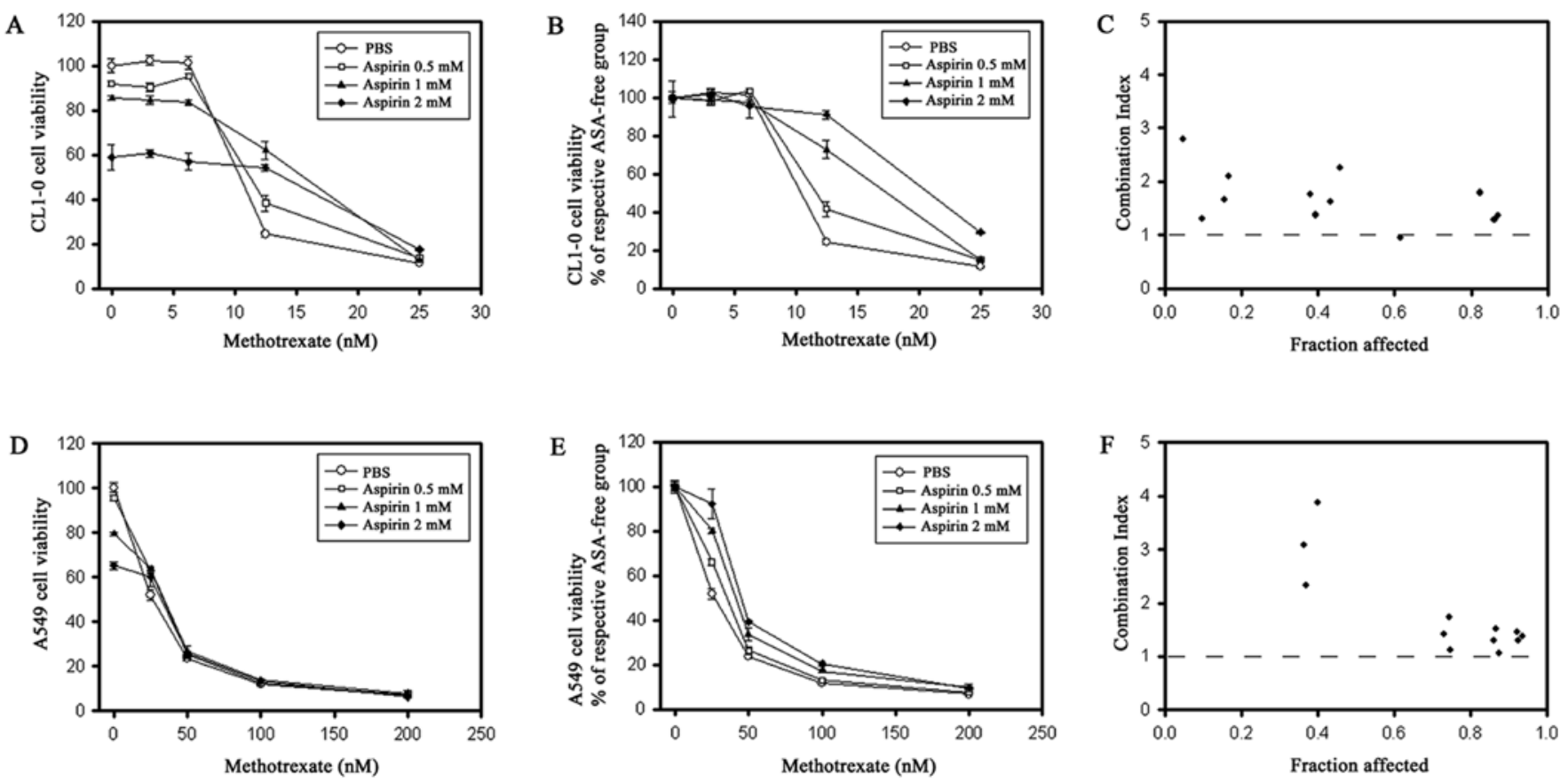

Figure 1. Antagonism of methotrexate (MTX) and aspirin (ASA) in CL1-0 (A-C) and A549 (D-F) cells, as evaluated by SRB staining assay. Cells were treated with various concentrations of MTX in the presence of PBS (circle), $0.5 \mathrm{mM}$ ASA (square), $1 \mathrm{mM}$ ASA (triangle), or $2 \mathrm{mM}$ ASA (rhombus) for $72 \mathrm{~h}$ and then assayed by SRB staining. Relative cell viability (\% of PBS control) is expressed as mean \pm SE. Viability curves (A and D) were further normalized to the viability of MTX-free cells treated with each ASA concentration, respectively (B and E). Combination index (CI) plots of MTX + ASA were generated in relation to cell survival inhibition (fraction affected) (C and F), where $\mathrm{CI}>1,<1$, and $=1$ indicate antagonism, synergism, and additive effect, respectively. PBS, phosphate-buffered saline.

remained), respectively, when compared to the control, treatment with the combination of ASA + MTX only resulted in a $46 \%$ decrease (i.e., $54 \%$ viability) instead of a predicted $85 \%$ decrease $(=100 \%-60 \% \times 25 \%)$ if the combination treatment would have been additive. A decrease in more than $85 \%$ would be expected if the combination effect was synergistic. Of note, the antagonistic effect of the MTX + ASA combination was also shown by the upper-right shift in the MTX survival curves following the addition of increasing doses of ASA to MTX (Fig. 1B). To quantitatively determine the magnitude of the antagonistic effect of the MTX + ASA combination treatment, the CI method of Chou and Talalay $(23,24)$ was employed. Virtually all CI values in the CI plots were significantly $>1$ (Fig. 1C and F), indicating a strong antagonism. Similar results were also observed for the A549 cells (Fig. 1D-F).

Colony formation assays were performed to further demonstrate the effects of the combination treatment of MTX and ASA. Images of the colonies grown in the presence or absence of various drugs are shown in Fig. 2A (CL1-0) and Fig. 2C (A549). While CL1-0 and A549 cells were different in sensitivity to ASA, marked antagonistic effects were observed in both CL1-0 and A549 cells when the two drugs were combined (Fig. 2B and D).

MTX-mediated $S$ phase arrest is antagonized by ASA. The effects of ASA on the cell cycle were examined in our previous study (25). Here, we assessed the effects of ASA on MTX-mediated alterations in the cell cycle. As shown in Fig. 3A (upper panel), while MTX alone induced a significant accumulation of CL1-0 cells in the S phase accompanied by a marked decrease in the number of cells in the G0/G1 phase, co-treatment with ASA effectively reversed these changes. Cyclin $A$ is an $S$ phase-specific regulatory protein that functions to induce mitosis. Expression of cyclin A is normally low in G1 phase but increases in $\mathrm{S}$ phase. Consistent with the blockade of $S$ to $\mathrm{G} 2 / \mathrm{M}$ phase transition, MTX treatment resulted in a marked accumulation of cyclin A protein (Fig. 3A, lower panel). Moreover, the MTX-mediated cyclin A accumulation was reversed by co-treatment with ASA. Notably, combination treatment with MTX + ASA resulted in a marked decrease in the number of CL1-0 cells in the G2/M phase. Similar results were obtained using A549 cells (Fig. 3B).

ASA prevents MTX-mediated apoptosis via inhibition of caspase-3 activation and upregulation of Bcl-2 expression. We next examined the effects of MTX and ASA treatments, individually and in combination, on cell cycle progression and apoptosis after $72 \mathrm{~h}$. Consistent with the 24-h treatment results in the CL1-0 cells, concomitant addition of ASA resulted in a significant reversal of MTX-mediated S phase arrest and depletion of G0/G1 phase cells (Fig. 4A). Importantly, the number of MTX-mediated apoptotic A549 cells was significantly reduced by ASA (Fig. 4B, left). The antagonistic effect of ASA against MTX was further supported by the result of the western blot analysis (Fig. 4B, right). While MTX treatment caused a reduction in Bcl-2 and pro-caspase 3, ASA treatment had an opposite effect. More importantly, following MTX + ASA co-treatment, the MTX-mediated effects on $\mathrm{Bcl}-2$ and pro-caspase 3 were also reversed. 

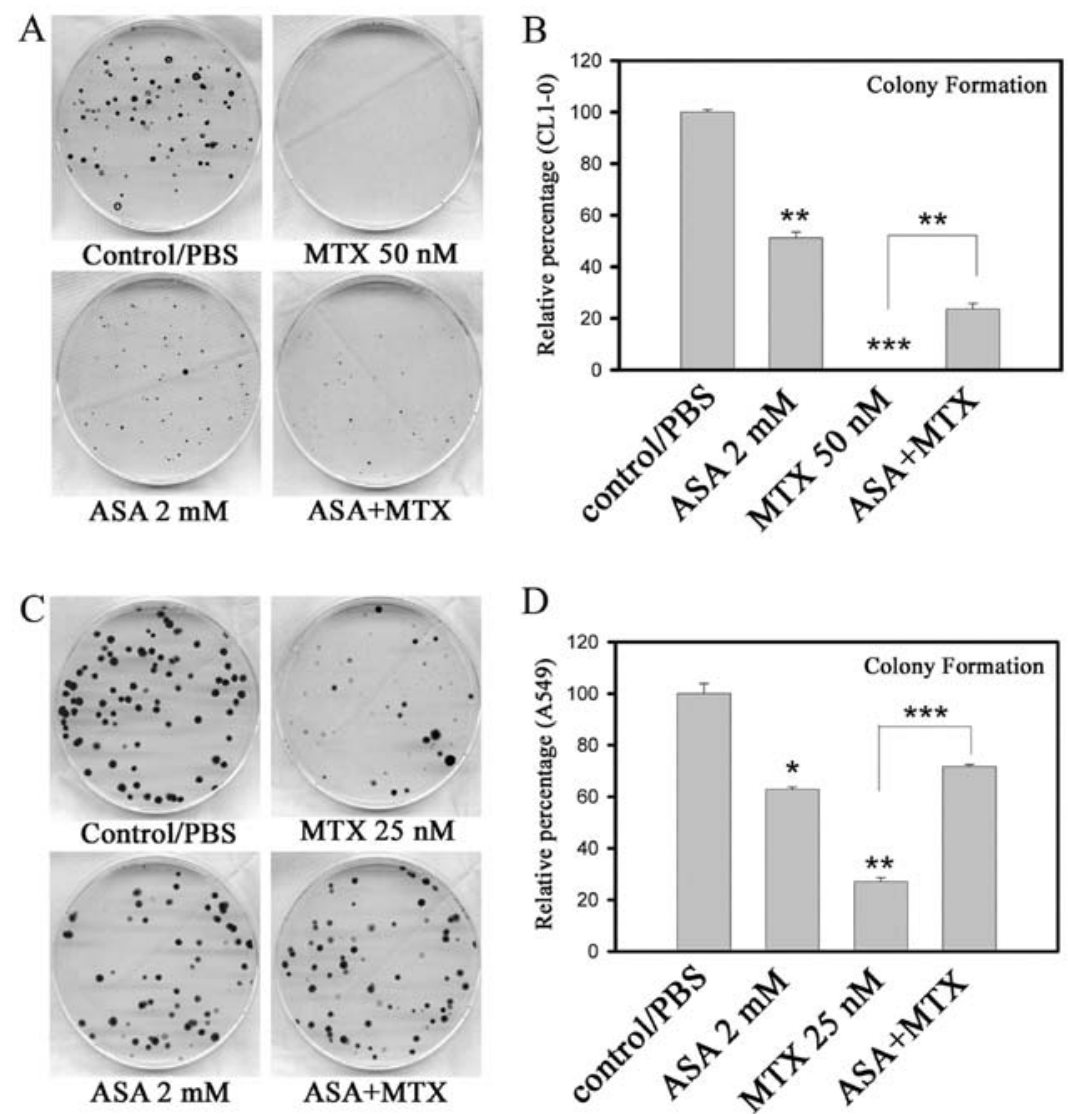

Figure 2. Antagonism of methotrexate (MTX) and aspirin (ASA) in CL1-0 (A and B) and A549 (C and D) cells, as evaluated by colony formation assay. Images of colony formation (A and C) and the relative number of colonies are shown (B and D). Error bars, SEM ( $\mathrm{n}=3$ ). ${ }^{*} \mathrm{P}<0.05,{ }^{* * *} \mathrm{P}<0.01$ and ${ }^{* * * *} \mathrm{P}<0.001$ for the comparisons indicated.

A

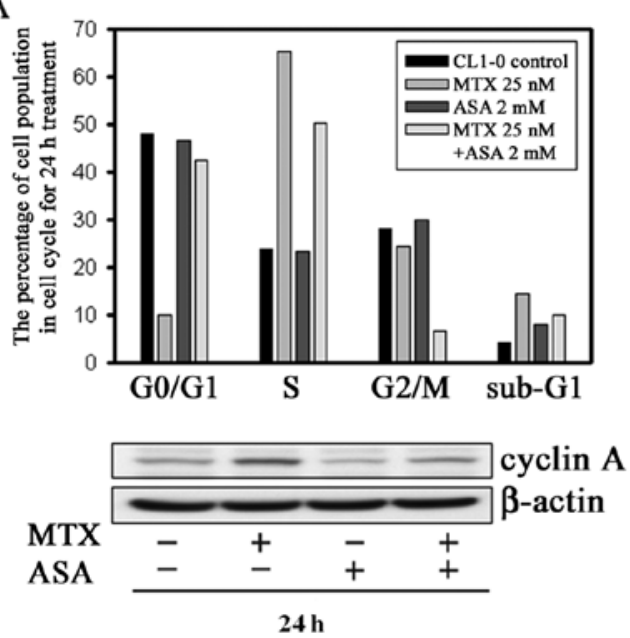

B

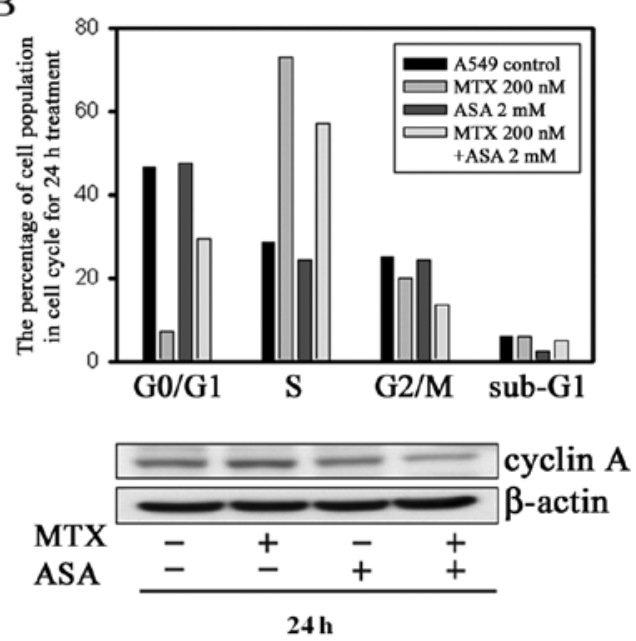

Figure 3. Effects of aspirin (ASA) (2 mM) and methotrexate (MTX) (25 nM for CL1-0, $200 \mathrm{nM}$ for A549), alone or in combination, on the cell cycle were determined for CL1-0 (A) and A549 (B) cells. The percentages of cells in the G0/G1, S, G2/M and sub-G1 phases were determined by flow cytometry after PI staining. Cell lysates were analyzed by western blotting for cyclin A. $\beta$-actin served as the loading control.

ASA antagonizes the MTX-mediated FAS protein level, but not DHFR. To assess whether expression of DHFR and FAS is correlated with the antagonism between ASA and MTX, the treated cells were harvested and analyzed by western blotting and RT-PCR (Fig. 5). DHFR protein levels were upregulated by MTX in both CL1-0 and A549 cells. Notably, while ASA alone had no effect on the DHFR and FAS protein levels, MTX-induced upregulation of FAS, but not DHFR, was reversed by ASA in A549 cells (Fig. 5A, right). This indicates that MTX-mediated apoptosis of A549 cells depends on an increased level of FAS. DHFR and FAS were not affected at the mRNA level (Fig. 5B). 
A
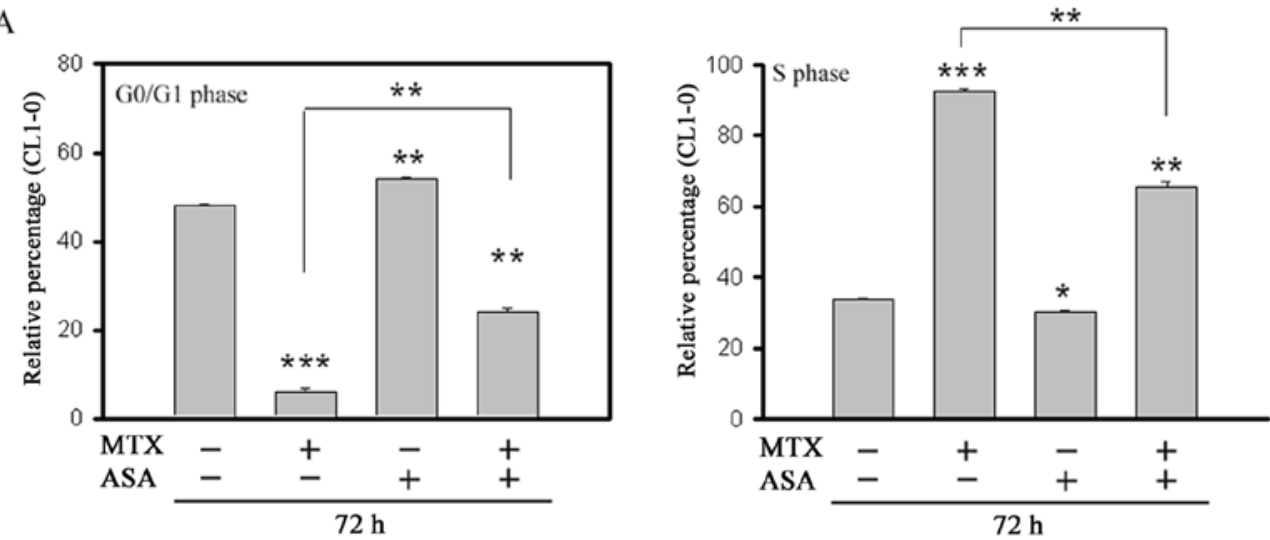

B
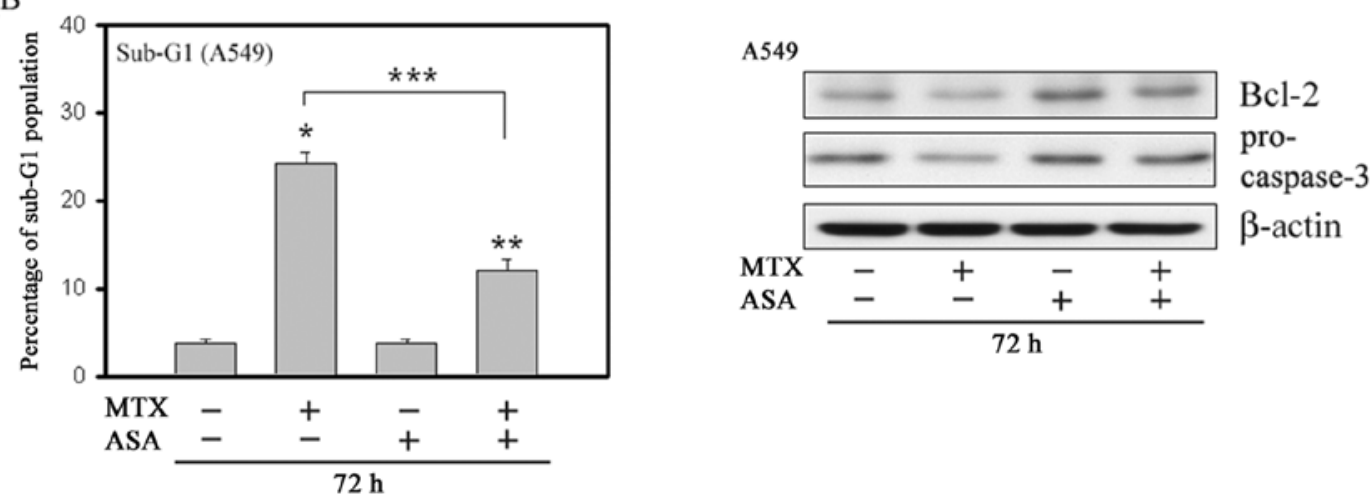

Figure 4. Effects of aspirin (ASA) (2 mM) and methotrexate (MTX) (CL1-0, $25 \mathrm{nM}$; A549, $200 \mathrm{nM}$ ), alone or in combination, on the cell cycle were determined after treatment for $72 \mathrm{~h}$. The percentage of CL1-0 cells in the G0/G1 phase (A, left) and S phase (A, right) was determined by flow cytometry after PI staining. The percentage of A549 cells in sub-G1 phase was determined by flow cytometry after PI staining (B, left). Cell lysates of A549 were analyzed by western blotting for $\mathrm{Bcl}-2$ and pro-caspase-3 (B, right). $\beta$-actin served as the loading control. Error bars, $\mathrm{SEM}(\mathrm{n}=3)$. ${ }^{*} \mathrm{P}<0.05,{ }^{* * *} \mathrm{P}<0.01$ and ${ }^{* * *} \mathrm{P}<0.001$ for the comparisons indicated.

A

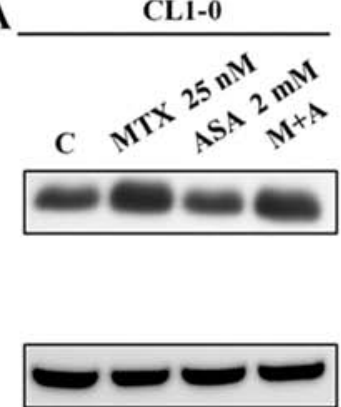

A549

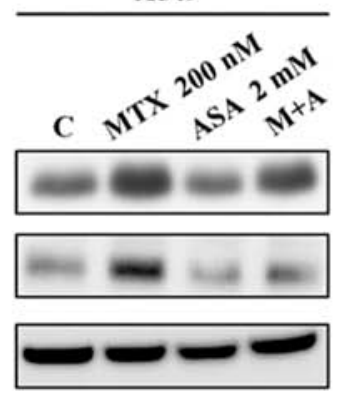

$\mathbf{B}$

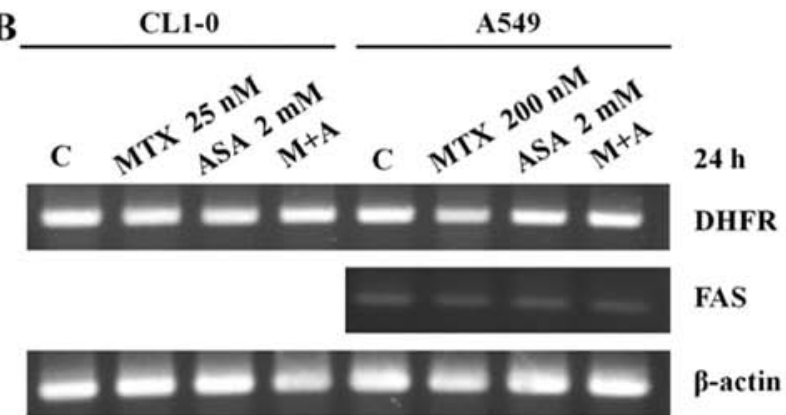

Figure 5. Effects of aspirin (ASA) and methotrexate (MTX) (at concentrations indicated), alone or in combination, on the protein (A, western blotting) and mRNA [B, RT-PCR] levels of dihydrofolate reductase (DHFR) and FAS were determined after treatment for $24 \mathrm{~h}$. $\beta$-actin was the internal control. $\mathrm{M}+\mathrm{A}=\mathrm{MTX}+\mathrm{ASA}$.

DHFR and COX-1/COX-2 are involved in MTX-mediated cancer cell growth inhibition. We aimed to ascertain whether DHFR activity is involved in the antagonistic effect of MTX and ASA co-treatment with folate. As shown in Fig. 6A-D, both the MTX-mediated growth inhibition (comparison of $3^{\text {rd }}$ and $4^{\text {th }}$ bar) and the MTX + ASA co-treatment-mediated growth inhibition (comparison of the $7^{\text {th }}$ and $8^{\text {th }}$ bar) were reversed, completely or partially, by folic acid in both cell lines. Folic acid did not affect the ASA-induced growth inhibition (comparison of the $5^{\text {th }}$ and $6^{\text {th }}$ bar). MTX achieves its cytotoxic effect through inhibition of the folate-dependent enzyme, DHFR, and our results indicate that inhibition of DHFR was involved not only in the MTX-mediated growth inhibition but also in the antagonism between MTX and ASA. Moreover, Fig. 7A and B shows that starvation pretreatment protected the cells from MTX treatment, presumably due to starvation-caused G1 phase arrest. The G1 phase synchronization can protect cancer cells from MTX-mediated cytotoxicity in the $S$ phase. In order to elucidate whether these ASA effects were mediated through COX-1 or COX-2 inhibi- 
A

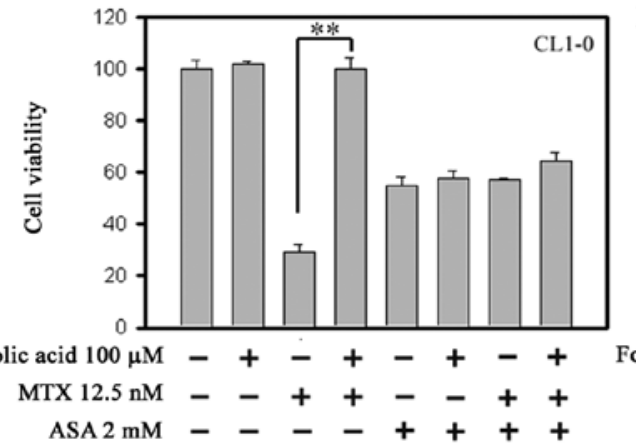

B

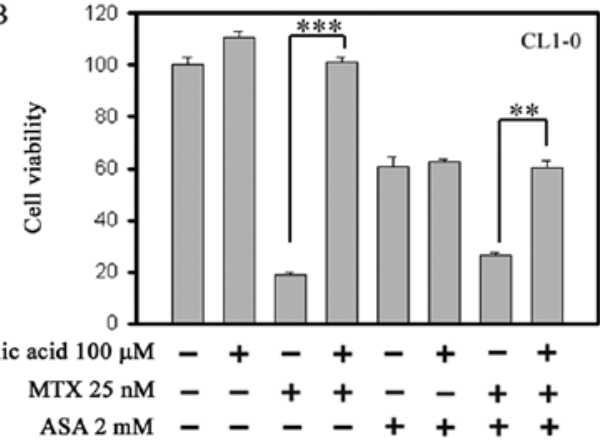

C

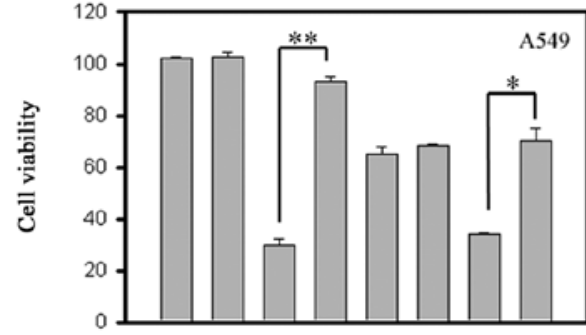

$\mathrm{D}$

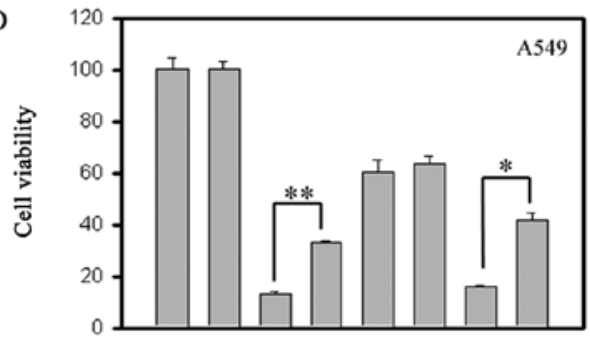

MTX $50 \mathrm{nM}--++-\infty+$

ASA $2 \mathrm{mM}----++++$

Figure 6. Antagonistic anticancer effect of methotrexate (MTX) + aspirin (ASA) is dihydrofolate reductase (DHFR)-dependent. Cells were treated with individual drugs alone or in combination at concentrations indicated or without treatment for $72 \mathrm{~h}$, then assayed by SRB staining for cell viability. As shown, folic acid $100 \mu \mathrm{M}$ did not reverse the effect of ASA in either CL1-0 (A and B) or A549 (C and D) cells. Folic acid alone at $100 \mu \mathrm{M}$ did not affect cell viability. In addition, the results of folic acid and MTX co-treatment revealed that the MTX-mediated inhibition of cell proliferation depends on a decreased DHFR activity (B and C). Error bars, SEM $(n=3) .{ }^{*} \mathrm{P}<0.05,{ }^{* *} \mathrm{P}<0.01$ and ${ }^{* * *} \mathrm{P}<0.001$ as compared with the control or the indicated bar.
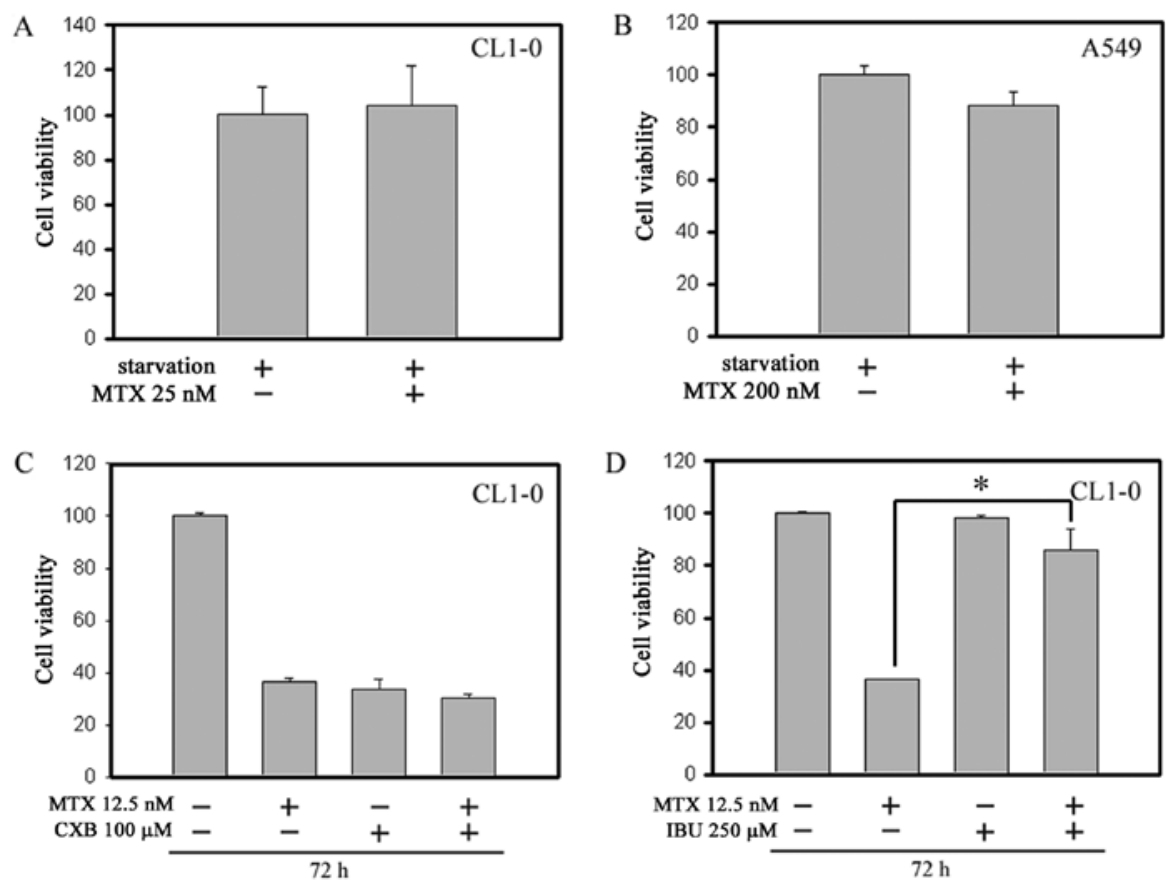

Figure 7. G1 phase cell accumulation may be involved in the antagonistic effect of methotrexate (MTX) + aspirin (ASA). CL1-0 (A) and A549 (B) cells were pretreated with starvation, and then with or without MTX for $72 \mathrm{~h}$. Cells were then assayed by SRB staining. CL1-0 (C and D) cells were treated with MTX $12.5 \mathrm{nM}$ with or without various NSAIDs (IBU, a non-selective COX-1/2 inhibitor; CXB, a specific COX-2 inhibitor) at indicated concentrations for $72 \mathrm{~h}$ and then assayed by SRB staining. Error bars, SEM $(n=3) .{ }^{*} \mathrm{P}<0.05,{ }^{* *} \mathrm{P}<0.01$ and ${ }^{* * *} \mathrm{P}<0.001$ as compared with the control or the indicated bar.

tion, we compared the COX-2-selective inhibitor CXB and the non-selective inhibitor IBU. As shown in Fig. 7C and D, while CXB also exhibited antagonism with MTX to some extent, IBU exerted a significantly more potent antagonism with MTX, indicating that both COX-1 and COX-2 are involved. 


\section{Discussion}

While toxicity is common when ASA or NSAIDs are used with MTX to treat RA (26), MTX and ASA are prescribed as the cornerstone of therapy for RA $(6,7,14,27,28)$. In addition, MTX is a clinically useful blocker of DHFR $(2,29)$, and shows efficacy in the treatment of acute leukemias and a number of types of solid tumors. MTX or ASA may be used in monotherapy or in combination with other agents. In the present study, the combination treatment with MTX + ASA was compared with treatment of each drug alone in lung cancer cells by evaluating changes in cell survival, cell cycle progression, cell proliferation and apoptotic cell death. Individually ASA and MTX are effective in the treatment of cancer; however, drug antagonism may pose a major obstacle to their effectiveness when they are combined.

MTX acts specifically in the S phase, and therefore exerts its activity in a cell cycle-specific manner (3). Recently, we reported that ASA induces G1 phase accumulation in CL1-0 and A549 lung cancer cells (25), indicating that ASA controls cell cycle progression, and this may be the underlying mechanism that affects the therapeutic efficacy of MTX. Additionally, results of this study found that serum-starved cells were also resistant to MTX (Fig. 7), presumably through synchronizing cells in the G1 phase and inducing growth arrest, an effect similar to that induced by ASA. The observation that both COX-1 and COX-2 inhibitors antagonized the antineoplastic effect of MTX is important. COX-1/2 inhibitors, including IBU and CXB, have been shown to induce a blockade of the G1 to $S$ phase transition and E2F inhibition $(30,31)$, and these effects may have contributed to their antagonizing effects against the efficacy of MTX. Thus, we hypothesized that concomitant use of ASA decreases the MTX-mediated S phase arrest and plays a role in quenching the $\mathrm{G} 1$ to $\mathrm{S}$ phase transition to protect cells from MTX-mediated cytotoxicity. Additionally, the level of cyclin A is low during G1 phase but begins to accumulate at the onset of the $\mathrm{S}$ phase and contributes to the process of the $S$ phase (32), and subsequently, is degraded during the prometaphase (33). Here, we showed that the MTX-induced growth inhibition was associated with a marked $\mathrm{S}$ phase arrest as well as a significant accumulation of cyclin A. Generally, downregulation of cyclin A results in cell cycle arrest in the $\mathrm{S}$ phase. The accumulation of cyclin A suggests that the MTX-induced S phase arrest was the result of a blockade of DNA synthesis, instead of the result of a direct regulation of the cyclin-Cdk pathway. Moreover, ASA may decrease the MTX-mediated accumulation of cells in the $S$ phase and cyclin A by maintaining cells in the G1 phase.

Caspase- 3 and Bcl-2 proteins play a critical role in determining the threshold of apoptotic cell death. Here, we demonstrated that ASA treatment may protect cells from apoptosis through its ability to reverse the MTX-mediated upregulation of caspase- 3 and downregulation of Bcl-2. The FAS death receptor is known to be expressed not only in immune cells but also in various types of tumor cells. Binding of FAS to its ligand, FasL, triggers a signaling cascade that leads to apoptosis (34). However, recent evidence suggests that intracellular FAS can also be activated via a FasL-independent pathway (35). During tumor development, expression of FasL was found to be increased and was associated with decreased expression of FAS in solid tumors (36). Collectively, restoration of the Fas/FasL pathway is a viable approach for novel therapeutic strategies (37). In the present study, MTX treatment increased the FAS protein level that may have had an effect on the cytotoxicity of MTX. Importantly, while treatment with ASA alone did not affect the FAS level, ASA significantly antagonized the MTX-mediated increase in FAS protein. The data shown in Fig. 5 suggest that the decreased MTX-mediated apoptosis by ASA was likely through the downregulation of FAS. Since the FAS/FasL system is important in inducing cancer cell apoptosis (35), the effect of the downregulation of FAS by ASA may present a novel mechanism underlying the MTX + ASA antagonism that warrants further in-depth investigation.

Antifolates are classic antitumor agents that inhibit key enzymes in DNA synthesis, i.e., DHFR $(38,39)$. The rhythmic change in MTX efficacy was observed to correspond to changes in the DHFR activity of cells (3). MTX inhibits cancer cell proliferation through tight-binding and by depletion of DHFR activity, and it was thus important to elucidate whether DHFR activity is involved in the MTX + ASA antagonism. Fig. 6 shows that almost all of the MTX-treated cancer cells were recovered in terms of viability following folic acid addition. Moreover, addition of folic acid reversed the MTX-mediated anticancer effect and the antagonism noted following the MTX + ASA combination treatment. The ASA-mediated anti-proliferative effect noted following treatment with ASA alone was not affected. Folic acid also restored the effects of MTX-mediated DHFR inhibition and DNA replication, as well as the transition from $S$ phase. The results suggest that DHFR activity is involved in both the MTX-mediated cytotoxic effect and the antagonism observed following combination treatment with MTX + ASA. Several reports have described that the amplification of DHFR is a common mechanism of resistance to MTX (40-43). Previous studies have indicated that DHFR expression is regulated by E2F-1 $(38,39)$. And E2F has also been found to be expressed in a cell cycle-dependent manner and is essential for G1/S phase transition. Our previous results suggest that ASA inhibits E2F-1 expression (25), indicating that ASA may control cell cycle progression and thereby may affect MTX efficacy. As shown in Fig. 5, MTX exposure upregulated the expression of DHFR protein but not its mRNA transcript, indicating that the ASA-mediated E2F-1 downregulation was not involved in the alteration of DHFR in this study. Previous studies $(40,44,45)$ have shown that DHFR protein regulates its own transcript translation through direct binding to its own mRNA; and thereby constitutes a translational autoregulation loop. Hence, the adaptive mechanism may allow cells to rapidly respond and to decrease MTX sensitivity (45). Binding of MTX to DHFR inhibits DHFR activity as well as the interaction of the DHFR protein with its mRNA. In the present study, we also observed the adaptive effect of DHFR translational upregulation when the lung cancer cells were treated with MTX. In contrast, ASA did not affect the DHFR translational autoregulation either with or without MTX, suggesting that the ASA-mediated attenuation of MTX sensitivity was independent of this DHFR adaptive mechanism. Taken together, our data revealed that pharmacologic concentrations of ASA can antagonize the 
efficacy of the chemotherapeutic agent MTX. These results are of high clinical relevance given the widespread use of NSAIDs and COX-1/2 inhibitors. The results also suggest that any agent that causes G1 accumulation may also exert an antagonism against MTX and adversely influence the treatment outcome of MTX therapy. Further studies are required to address the precise causes and clinical implications of the combination of MTX and NSAIDs for RA and cancer therapy.

\section{Acknowledgements}

This study was supported by the National Health Research Institutes (CA-099-PP-09), Department of Health (DOH100TD-C-111-004, DOH100-TD-C-111-008) and Wan Fang Hospital (100swf15), Taiwan, R.O.C.

\section{References}

1. Fotoohi AK and Albertioni F: Mechanisms of antifolate resistance and methotrexate efficacy in leukemia cells. Leuk Lymphoma 49: 410-426, 2008

2. Hider SL, Bruce IN and Thomson W: The pharmacogenetics of methotrexate. Rheumatology 46: 1520-1524, 2007.

3. Yamauchi A, Ichimiya T, Inoue K, Taguchi Y, Matsunaga N, Koyanagi S, Fukagawa T, Aramaki H, Higuchi S and Ohdo S: Cell-cycle-dependent pharmacology of methotrexate in HL-60. J Pharmacol Sci 99: 335-341, 2005.

4. Cronstein BN: Low-dose methotrexate: a mainstay in the treatment of rheumatoid arthritis. Pharmacol Rev 57: 163-172, 2005.

5. Tian $\mathrm{H}$ and Cronstein $\mathrm{BN}$ : Understanding the mechanisms of action of methotrexate: implications for the treatment of rheumatoid arthritis. Bull NYU Hosp Jt Dis 65: 168-173, 2007.

6. Weinblatt ME, Coblyn JS, Fox DA, Fraser PA, Holdsworth DE, Glass DN and Trentham DE: Efficacy of low-dose methotrexate in rheumatoid arthritis. N Engl J Med 312: 818-822, 1985.

7. Chan ES and Cronstein BN: Molecular action of methotrexate in inflammatory diseases. Arthritis Res 4: 266-273, 2002.

8. Wessels JA, van der Kooij SM, le Cessie S, Kievit W, Barerra P, Allaart CF, Huizinga TW and Guchelaar HJ: A clinical pharmacogenetic model to predict the efficacy of methotrexate monotherapy in recent-onset rheumatoid arthritis. Arthritis Rheum 56: 1765-1775, 2007.

9. Hani N, Casper C, Groth W, Krieg T and Hunzelmann N: Stevens-Johnson syndrome-like exanthema secondary to methotrexate histologically simulating acute graft-versus-host disease. Eur J Dermatol 10: 548-550, 2000.

10. Naidu MU, Ramana GV, Rani PU, Mohan IK, Suman A and Roy P: Chemotherapy-induced and/or radiation therapy-induced oral mucositis - complicating the treatment of cancer. Neoplasia 6: 423-431, 2004.

11. Tomoda R, Seto M, Hioki Y, Sonoda J, Matsumine A, Kusuzaki K and Uchida A: Low-dose methotrexate inhibits lung metastasis and lengthens survival in rat osteosarcoma. Clin Exp Metastasis 22: 559-564, 2005.

12. Morison WL, Momtaz K, Parrish JA and Fitzpatrick TB: Combined methotrexate-PUVA therapy in the treatment of psoriasis. J Am Acad Dermatol 6: 46-51, 1982.

13. Sweeney CJ, Takimoto CH, Latz JE, Baker SD, Murry DJ, Krull JH, Fife K, Battiato L, Cleverly A, Chaudhary AK, Chaudhuri T, Sandler A, Mita AC and Rowinsky EK: Two drug interaction studies evaluating the pharmacokinetics and toxicity of pemetrexed when coadministered with aspirin or ibuprofen in patients with advanced cancer. Clin Cancer Res 12: 536-542, 2006.

14. Pablos JL: Aspirin antiplatelet therapy and nonsteroidal antiinflammatory drugs: comment on the 2002 update of the American College of Rheumatology Guidelines for the Management of Rheumatoid Arthritis. Arthritis Rheum 46: 3102, 2002.

15. Moysich KB, Menezes RJ, Ronsani A, Swede H, Reid ME, Cummings KM, Falkner KL, Loewen GM and Bepler G: Regular aspirin use and lung cancer risk. BMC Cancer 2: 31, 2002.
16. Van Dyke AL, Cote ML, Prysak G, Claeys GB, Wenzlaff AS and Schwartz AG: Regular adult aspirin use decreases the risk of non-small cell lung cancer among women. Cancer Epidemiol Biomarkers Prev 17: 148-157, 2008.

17. Cuzick J, Otto F, Baron JA, Brown PH, Burn J, Greenwald P, Jankowski J, La Vecchia C, Meyskens F, Senn HJ and Thun M: Aspirin and non-steroidal anti-inflammatory drugs for cancer prevention: an international consensus statement. Lancet Oncol 10: 501-507, 2009.

18. Kremer JM and Hamilton RA: The effects of nonsteroidal antiinflammatory drugs on methotrexate (MTX) pharmacokinetics: impairment of renal clearance of MTX at weekly maintenance doses but not at $7.5 \mathrm{mg}$. J Rheumatol 22: 2072-2077, 1995.

19. Stewart CF, Fleming RA, Germain BF, Seleznick MJ and Evans WE: Aspirin alters methotrexate disposition in rheumatoid arthritis patients. Arthritis Rheum 34: 1514-1520, 1991.

20. Fries JF, Singh G, Lenert L and Furst DE: Aspirin, hydroxychloroquine, and hepatic enzyme abnormalities with methotrexate in rheumatoid arthritis. Arthritis Rheum 33: 1611-1619, 1990.

21. Chu YW, Yang PC, Yang SC, Shyu YC, Hendrix MJ, Wu R and Wu CW: Selection of invasive and metastatic subpopulations from a human lung adenocarcinoma cell line. Am J Respir Cell Mol Biol 17: 353-360, 1997.

22. Keepers YP, Pizao PE, Peters GJ, van Ark-Otte J, Winograd B and Pinedo HM: Comparison of the sulforhodamine B protein and tetrazolium (MTT) assays for in vitro chemosensitivity testing. Eur J Cancer 27: 897-900, 1991.

23. Chou TC: Theoretical basis, experimental design, and computerized simulation of synergism and antagonism in drug combination studies. Pharmacol Rev 58: 621-681, 2006.

24. Chou TC and Talalay P: Quantitative analysis of dose-effect relationships: the combined effects of multiple drugs or enzyme inhibitors. Adv Enzyme Regul 22: 27-55, 1984.

25. Yan KH, Yao CJ, Chang HY, Lai GM, Cheng AL and Chuang SE: The synergistic anticancer effect of troglitazone combined with aspirin causes cell cycle arrest and apoptosis in human lung cancer cells. Mol Carcinog 49: 235-246, 2010.

26. Rooney TW, Furst DE, Koehnke R and Burmeister L: Aspirin is not associated with more toxicity than other nonsteroidal antiinflammatory drugs in patients with rheumatoid arthritis treated with methotrexate. J Rheumatol 20: 1297-1302, 1993.

27. Kurth T, Hennekens CH, Buring JE and Gaziano JM: Aspirin, NSAIDs, and COX-2 inhibitors in cardiovascular disease: possible interactions and implications for treatment of rheumatoid arthritis. Curr Rheumatol Rep 6: 351-356, 2004.

28. Ranganathan P: An update on methotrexate pharmacogenetics in rheumatoid arthritis. Pharmacogenomics 9: 439-451, 2008.

29. Krajinovic M and Moghrabi A: Pharmacogenetics of methotrexate. Pharmacogenomics 5: 819-834, 2004.

30. Bock JM, Menon SG, Goswami PC, Sinclair LL, Bedford NS, Domann FE and Trask DK: Relative non-steroidal anti-inflammatory drug (NSAID) antiproliferative activity is mediated through p21-induced G1 arrest and E2F inhibition. Mol Carcinog 46: 857-864, 2007

31. Janssen A, Maier TJ, Schiffmann S, Coste O, Seegel M, Geisslinger G and Grösch S: Evidence of COX-2 independent induction of apoptosis and cell cycle block in human colon carcinoma cells after S- or R-ibuprofen treatment. Eur J Pharmacol 540: 24-33, 2006.

32. Resnitzky D, Hengst L and Reed SI: Cyclin A-associated kinase activity is rate limiting for entrance into $\mathrm{S}$ phase and is negatively regulated in G1 by p27Kip1. Mol Cell Biol 15: 4347-4352, 1995.

33. Mateo F, Vidal-Laliena M, Canela N, Busino L, Martinez-Balbas MA, Pagano M, Agell N and Bachs O: Degradation of cyclin A is regulated by acetylation. Oncogene 28: 2654-2666, 2009.

34. Gloire G, Charlier E and Piette J: Regulation of CD95/APO-1/ Fas-induced apoptosis by protein phosphatases. Biochem Pharmacol 76: 1451-1458, 2008.

35. Mollinedo F and Gajate C: Fas/CD95 death receptor and lipid rafts: new targets for apoptosis-directed cancer therapy. Drug Resist Updat 9: 51-73, 2006.

36. Kim R, Emi M, Tanabe K, Uchida Y and Toge T: The role of Fas ligand and transforming growth factor $\beta$ in tumor progression: molecular mechanisms of immune privilege via Fas-mediated apoptosis and potential targets for cancer therapy. Cancer 100: 2281-2291, 2004.

37. O'Brien DI, Nally K, Kelly RG, O'Connor TM, Shanahan F and $\mathrm{O}^{\prime}$ Connell J: Targeting the Fas/Fas ligand pathway in cancer. Expert Opin Ther Targets 9: 1031-1044, 2005. 
38. Sowers R, Toguchida J, Qin J, Meyers PA, Healey JH, Huvos A, Banerjee D, Bertino JR and Gorlick R: mRNA expression levels of E2F transcription factors correlate with dihydrofolate reductase, reduced folate carrier, and thymidylate synthase mRNA expression in osteosarcoma. Mol Cancer Ther 2: 535-541, 2003.

39. Slansky JE, Li Y, Kaelin WG and Farnham PJ: A protein synthesis-dependent increase in E2F1 mRNA correlates with growth regulation of the dihydrofolate reductase promoter. Mol Cell Biol 13: 1610-1618, 1993.

40. Skacel N, Menon LG, Mishra PJ, Peters R, Banerjee D, Bertino JR and Abali EE: Identification of amino acids required for the functional up-regulation of human dihydrofolate reductase protein in response to antifolate treatment. J Biol Chem 280: 22721-22731, 2005.

41. Mishra PJ, Humeniuk R, Longo-Sorbello GS, Banerjee D and Bertino JR: A miR-24 microRNA binding-site polymorphism in dihydrofolate reductase gene leads to methotrexate resistance. Proc Natl Acad Sci USA 104: 13513-13518, 2007.
42. Snijders AM, Hermsen MA, Baughman J, Buffart TE, Huey B, Gajduskova P, Roydasgupta R, Tokuyasu T, Meijer GA, Fridlyand $\mathrm{J}$ and Albertson DG: Acquired genomic aberrations associated with methotrexate resistance vary with background genomic instability. Genes Chromosomes Cancer 47: 71-83, 2008.

43. Bertino JR, Göker E, Gorlick R, Li WW and Banerjee D: Resistance mechanisms to methotrexate in tumors. Stem Cells 14: 5-9, 1996.

44. Ercikan-Abali EA, Banerjee D, Waltham MC, Skacel N, Scotto KW and Bertino JR: Dihydrofolate reductase protein inhibits its own translation by binding to dihydrofolate reductase mRNA sequences within the coding region. Biochemistry 36 : 12317-12322, 1997.

45. Hsieh YC, Skacel NE, Bansal N, Scotto KW, Banerjee D, Bertino JR and Abali EE: Species-specific differences in translational regulation of dihydrofolate reductase. Mol Pharmacol 76: 723-733, 2009. 